In very marasmic infants, when the weight is below $65 \%$ of the expected weight, and the basal requirements fall, less food will of course be required and allowance can be made for this by a simple calculation.

SUMMARY

The importance of the caloric intake in infant feeding is stressed and an outline of the reasoning behind the determination of the amount of food required at various ages is given. This applies equally to breast- and bottle-fed infants.

\title{
REFERENCES
}

Fleming, G. B. (1923-4). Quart. F. Med. 17, 339.

Gordon, H. H., Levine, S. Z. \& McNamara, H. (1947). Amer. F. Dis. Child. 73, 442.

Lusk, G. (1919). The Science of Nutrition, 3rd ed. London: W. B. Saunders Co.

Smellie, J. M. (1952). Brit. Y. Nutrit. 6, 220.

Waller, H. K. (1952). Brit. F. Nutrit. 6, 210.

\section{The Importance of Breast Feeding}

\section{By H. K. WALLER, British Hospital for Mothers and Babies, Woolwich, London, S.E. 18}

The implication in the title of my paper is that breast feeding has an advantage over artificial feeding. That indeed is my belief, but The Nutrition Society will not want belief but proof; and frankly I cannot bring forward any likely to convince it. The rate of infant mortality has been falling steadily in this country during the past 50 years; the period being notable for a great improvement in the safety of bottle feeding. There is no evidence that $I$ know to show the reduction in the death rate of babies owes anything to an increase in the number breast fed.

For such proof as there is of the importance of breast feeding we have to rely on carefully planned statistical surveys. Often quoted is one carried out by Grulee and his co-workers in Chicago between 1924 and 1929 (Grulee, Sanford \& Schwartz, 1935). The mortality rate of the 20,000 babies they reviewed was but II/1000; and among the wholly breast fed only $1 \cdot 6 / 1000$. These figures are so low that when published they seemed quite inapplicable to this country. Morbidity is much more difficult to assess, but they claimed that the incidence of infection was directly related to the method of feeding: $37 \%$ in the breast fed, $64 \%$ in the artificially fed. I will only quote one example of work in this country, where epidemic enteritis has always been a special risk to young bottle-fed babies. Despite the improvement in safety already mentioned, in a series of 216 cases of infantile gastro-enteritis, Gairdner (1945) found recently a death rate of $6 \mathrm{r} \%$ when breast feeding lasted for less than a month, and $28 \%$ if it had been prolonged beyond that time. I chose that example because in clinical practice there is ample, one might say daily, evidence that the ability to accommodate itself to artificial milk is least in the newborn and becomes progressively greater with the passage of time. So much so that by the age of 6 months there are not many who will not thrive on cow's milk. They thrive, that is 
to say, when judged by the standards which we usually employ, such as records of weight and height, the age at which balance in the upright position is attained, the date and order of dentition and so on. - In discussing these standards with parents, doctors, or at least the prudent among us, always allow a wide margin for the 'normal' in the individual. Here, however, an even greater reservation seems to me needed.

It is generally accepted that the differences in the composition of the milks of mammalian species have been evolved in accordance with the particular pattern of growth best suited to the young. Thus the young seal, which is suckled for a matter of 3 weeks only, increases in weight from about 30 to $90 \mathrm{lb}$. mainly by the deposition of fat. The mother's milk is said to contain $43 \%$ of it. Now surely the most impressive feature of the human baby's growth is the rapid development of the central nervous system. The brain reaches nearly two-thirds of adult size by the age of 2 years, and almost its full size by 7 years. I know of no nutritional studies on the bearing of infant feeding on this phenomenon. But I sometimes wonder whether we may not dismiss too lightly the possibility that the composition of human milk may be specially related to the rapid growth of nervous tissue; whether, in fact, the functional efficiency of the adult brain may not suffer from the substitution of bovine for human milk in the early stage of its growth. And if this seems too absurdly far fetched to put forward in seriousness, may I remind the reader how often we used to see in babies suffering from rickets-a deficiency disease-quite grave disturbances of the central nervous system; spasmus nutans, laryngismus, tetany and convulsions. Though I have no figures to support me, it is my impression that convulsions are considerably more common in bottle-fed than in breast-fed babies, and I think all paediatricians are agreed that the effect of convulsions in infancy can be very serious. (I hardly dare suggest that some part of the psychiatric therapy, which seems to be becoming an almost indispensable part of the up-bringing of children, may one day be replaced by dietetics, should we get to know more about the relationship at which I have hinted.)

A recent inquiry (Joint Committee of the Royal College of Obstetricians and Gynaecologists and the Population Investigation Committee, 1948) revealed that $43 \%$ of 13,000 babies were artificially fed by the age of 8 weeks, and that another $12 \%$ were partly so fed. We may thus suspect that soon after that age half the 13,000 were wholly bottle fed. It is clear that if the main risk of this method of feeding is to be reduced we need to know why it is that breast feeding ceases so early for so many. Unfortunately this large survey provides no answer, and the same holds good for many others of smaller size. For example, a careful review by Robinson (1943) in Liverpool of I 100 failures of lactation, showed no explanation of $40 \%$.

It is a problem $I$ have been studying for a number of years and have a few observations which perhaps are worth offering. In dairy science it is well established that the size of the milk yield of animals, as well as its security, depend on the degree to which the udder is regularly emptied. If this is true of the mammary gland in women, as $I$ think it is, then one finds in practice that it is often not recognized. There are many reasons for incomplete emptying at the start of lactation, especially the first lactation. The baby's contribution to emptying the breasts may be hampered by anatomical defects of the nipple. The initial yield may be greater than even a large 
infant can utilize. The newborn may be frail and weakly as, for example, when it is born prematurely; or it may be reluctant to feed because of illness or birth injury. And lastly the breasts' function of expelling the milk may be interfered with. Compared with these a true insufficiency (hypogalactia) seems to be uncommon, though it is often advanced as a main reason why many women cannot succeed. In Fig. I the yield is shown of a series of 400 women as they passed through the hospital wards. They were equally divided between primiparas and multiparas. Seventy-eight $\%$, or almost four-fifths of the 400 , were yielding $20 \mathrm{oz}$. milk, or more, on the roth day after delivery. If they were representative, the figure suggests that failure arises from an inability to maintain an originally satisfactory yield.

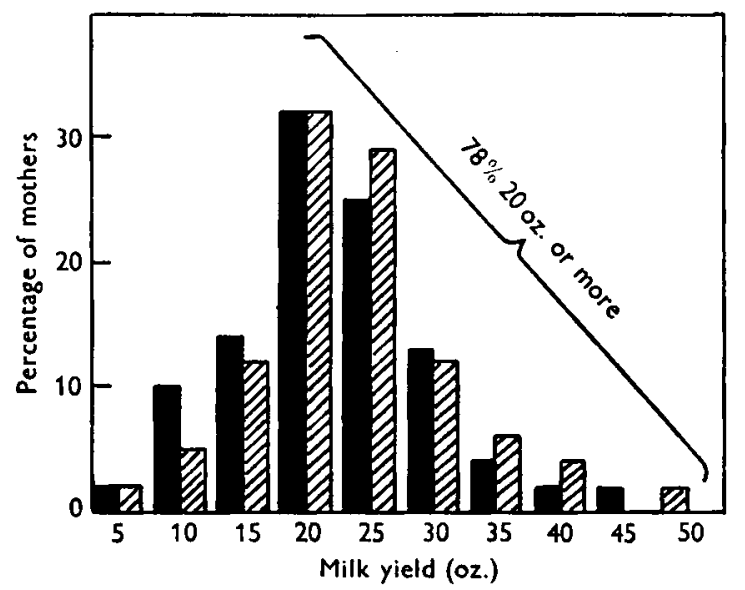

Fig. 1. Milk yield of a series of 400 women (200 primiparas and 200 multiparas) on the Ioth day post-partum. Solid columns, primiparas; hatched columns, multiparas.

A nipple that is tied to the deep structure of the breast and cannot be drawn far into the baby's mouth is a great obstacle to emptying, for when squeezed between the jaws it retracts towards the breast. The lactiferous sinuses are then out of reach. This defect is easily found by pinching just behind the nipple's base, and if detected early enough in pregnancy can be corrected, or much improved, by the use of the shield illustrated (Pl. I). It is worn under a brassiere which keeps the nipple pushed through the hole in the base of the shield and gradually stretches its attachment. Some degree of defect in one or both nipples is found in about $40 \%$ of our primigravidas. Figs. 2 and 3 show differences in the degree to which the newborn drains the breasts. In Fig. 2 emptying is almost complete, and lactation may be considered secure. In Fig. 3 there is a gross disproportion between the amount of milk produced and what the child can take. Only $43 \%$ of the yield is withdrawn. Here, unless the residual milk had been removed by hand, this woman's lactation would probably soon have ceased. She represents a large class who tell us they had too much milk at first, but that it left them when they got up. They are commonly accused of being unwilling to breast feed.

Fig. 4 illustrates the weekly yield of a young woman who gave birth to a baby weighing $2 \mathrm{lb} .2 \mathrm{oz} .(960 \mathrm{~g})$ at the 28 th week of her first pregnancy. It demonstrates 
how easily the yield can be preserved by the regular manual removal of the milk. The baby was not strong enough to feed direct from the breast until the 8th week. Soon afterwards it obtained all it needed, and only the excess was expressed. Later still demand and supply balanced. We teach all our patients during pregnancy the use of their hands for this purpose. There is not time to teach them between delivery and the start of milk secretion.

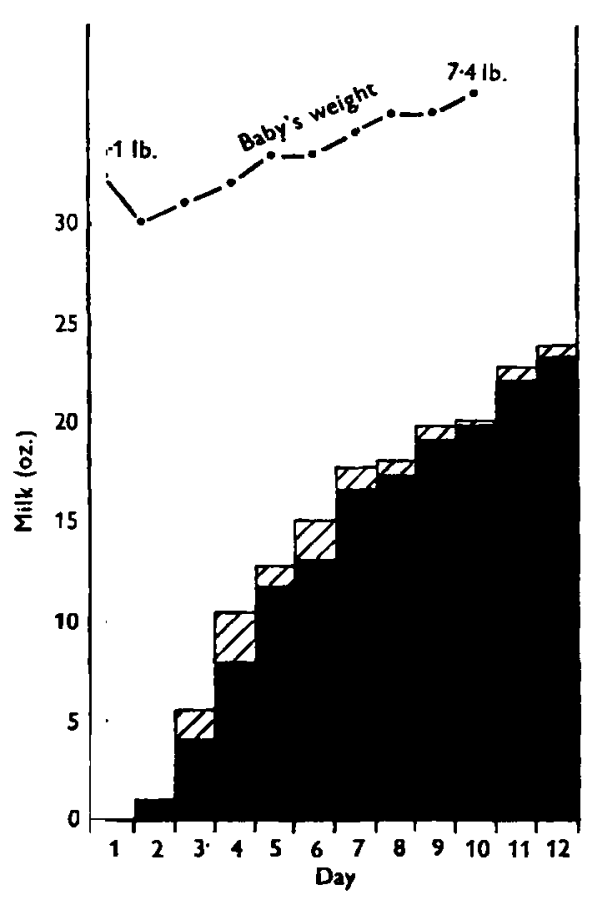

Fig. 2

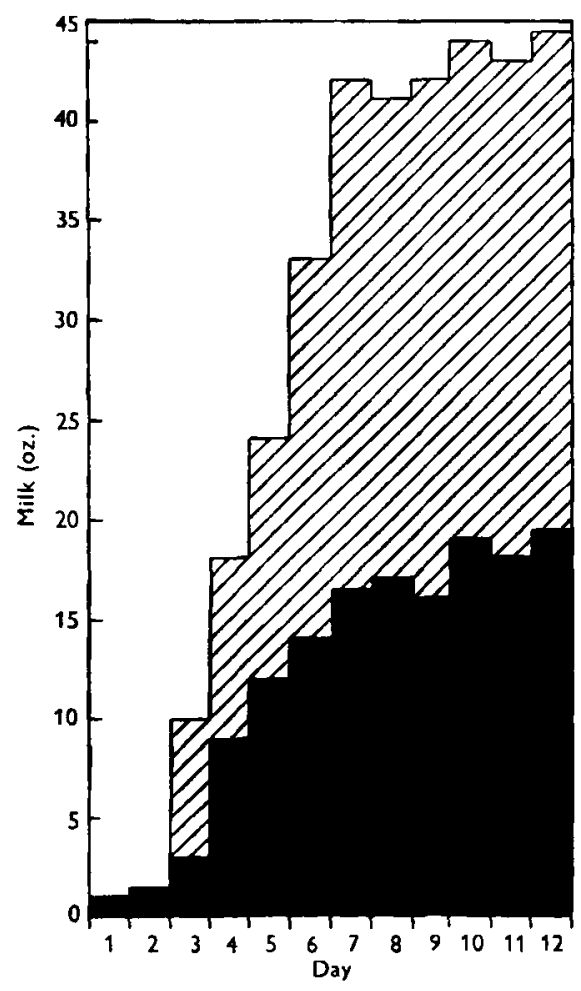

Fig. 3

Fig. 2. Almost complete emptying of the breast by newbom baby. Solid area, milk removed by baby; hatched area, residual milk removed by hand. Total yield in 12 days, 16702 ., removed by baby $156 \mathrm{oz}$, ratio $93 \%$.

Fig. 3. Partial emptying of the breast by newborn baby. Solid area, milk removed by baby; hatched area, residual milk removed by hand. Total yield $34 \mathrm{I}$ oz., removed by baby $147 \mathrm{oz}$., ratio $43 \%$. Birth weight of baby 6-2 lb.

Interference with the reflex expulsion of milk is often seen when the secretion starts rapidly and is copious. The breasts are then apt to become very overloaded. They may indeed be lumpy and oedematous, and then outflow is obstructed. This is difficult to deal with and is a common source of failure; for if the state of high milk tension persists for several days it is followed by resorption of milk and the changes of involution. If the danger is recognized early, it can be controlled by the judicious use of one of the preparations of oestrogen. Fig. 5 shows an example. Pain as an inhibitor of reflex expulsion has been mentioned, and there can be no question that suckling when the surface of the nipples has been broken can cause very acute pain. The 
remedy is not to allow the baby to suckle, and to remove the milk by hand until the breach in the surface is healed. This simple measure would by itself prevent many women from weaning their babies; it would also lessen the high incidence of acute lactational mastitis and breast abscess which give breast feeding such a bad reputation.

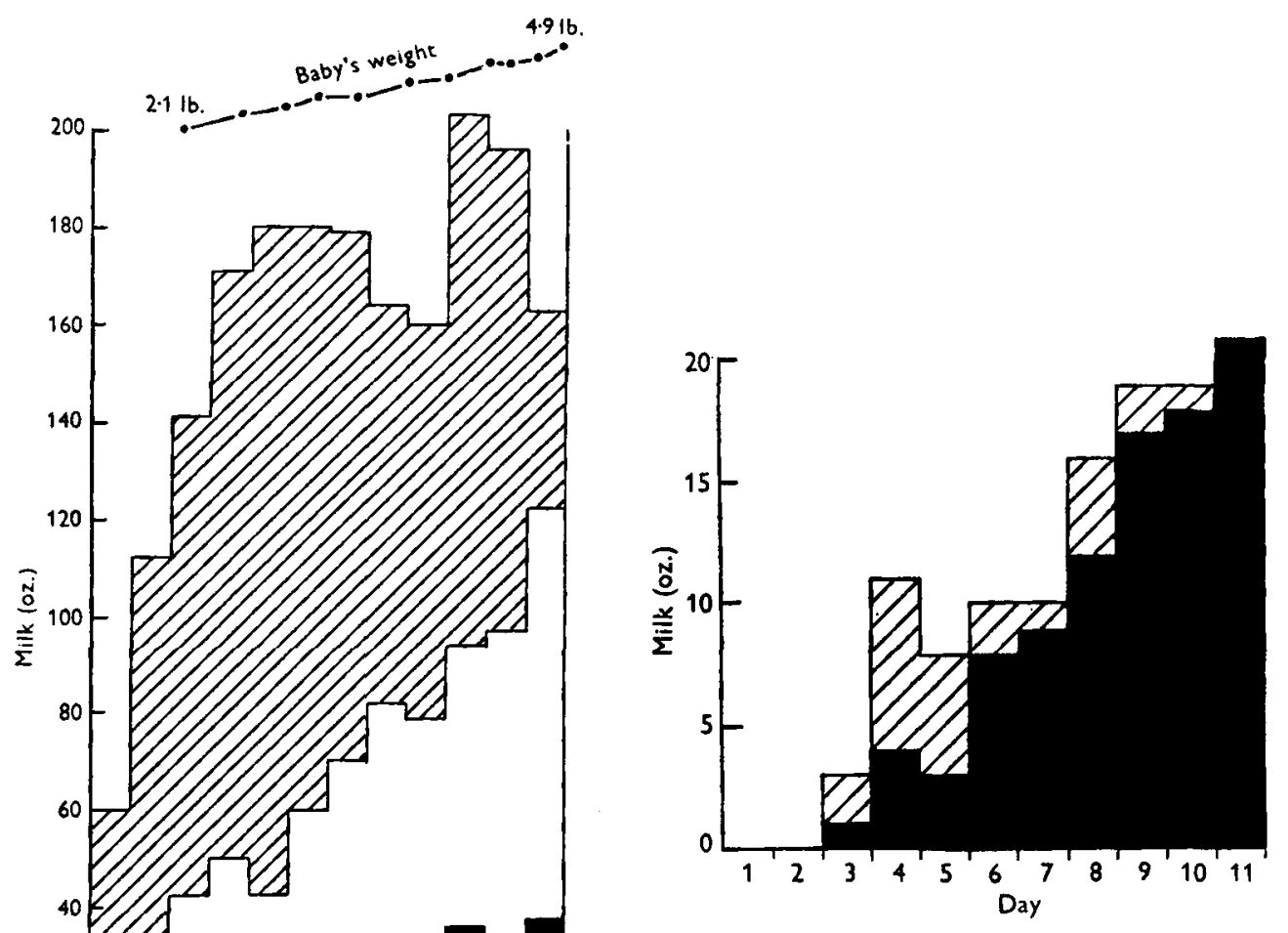

Fig. 5

Fig. 4. Weekly milk yield of mother of premature baby. Solid area, milk removed by baby; white area, milk removed by hand and given to baby by bottle; hatched area, milk removed by hand but not given to baby.

Fig. 5. Control of breast engorgement on 3 rd day by administration of stilboestrol and manual expression. Solid area, milk removed by baby; hatched area, residual milk removed by hand.

It has been the teaching at our hospital that, far from being a simple physiological function, the start of breast feeding is a difficult task for many women. To obtain adequate drainage of the breasts from the very outset calls for skilled attention to detail; with its aid it is interesting to see how often women are enabled to succeed who have failed previously with a succession of babies. Another striking fact is that, granted the right help, unwillingness to breast feed seems to be uncommon. Several 
H. K. WALLER. The importance of BrEast FEeding

Plate I

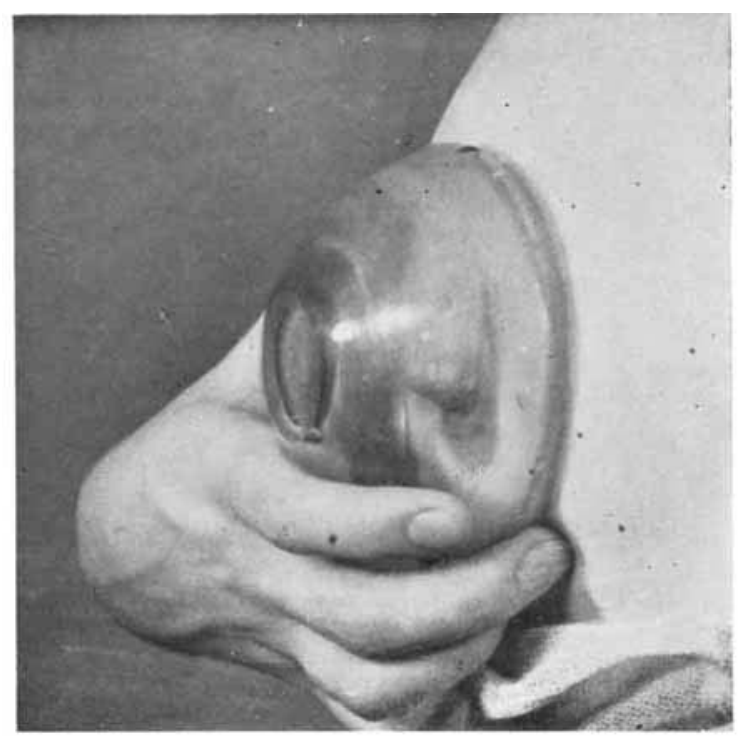

British Yournal of Nutrition, Vol. 6, No. 2 
series which we have followed beyond the lying-in period have shown it is not difficult for between 70 and $80 \%$ to continue to breast feed for 6 months and longer.

\section{EXPLANATION OF PLATE}

Pl. I. Breast shield to be worn during pregnancy for correcting defective nipples.

\section{REFERENCES}

Grulee, C. G., Sanford, H. N. \& Schwartz, H. (1935). F. Amer. med. Ass. I04, 1986.

Gairdner, P. (1945). Arch. Dis. Childh. 20, 22.

Joint Committee of the Royal College of Obstetricians and Gynaecologists and the Population Investigation Committee (1948). Maternity in Great Britain. London: Oxford University Press.

Robinson, M. (I943). Lancet, 244, 66.

\section{Composition of Human Milk and Factors Affecting It}

\section{By Mavis Gunther, Departments of Obstetrics and Child Welfare, University College Hospital, London, W.C. I}

The composition of breast milk is of interest primarily because it is the recipe of the most satisfactory food for a baby. It is also to some extent a measure of the mother's nutrition and an indication of the mother's food requirements. Its variation may help to reveal how milk is formed.

The secretion of the mammary gland varies during the course of lactation, starting during pregnancy and the first days after delivery as colostrum, changing to milk which again alters in composition with the passage of days and weeks. Eventually the secretion of full milk is succeeded by a secretion resembling colostrum. This has been called regression milk. After the first acceleration on the $3^{\text {rd }}$ or $4^{\text {th }}$ day the rate of secretion of milk is almost constant from hour to hour and day to day with a slow increase of about $\mathrm{I}-\mathrm{I} \frac{1}{2} \mathrm{oz}$. on the day's total in the course of a week to meet the baby's growing needs. The removal of milk, partly brought about by the mechanism of the baby's mouth, is aided by an expulsive mechanism within the breast. This, the draught reflex, may be impaired by emotion. The degree of emptying depends not only on the activity of the baby but on the vigour and timing of the draught and there is no clear end-point. The milk that is not removed at one feed is believed to be added to the subsequent secretion. As the fat globules of milk tend to remain in the gland, the fore-milk contains little fat, the hind-milk much more and the milk obtained at a feed or at a sampling may vary much in fat content.

Nitrogenous substances. The protein of breast secretion normally decreases rapidly in the first days and then more slowly throughout lactation; the first viscous material may contain as much as ro \% or more protein; towards the end of the ist week the percentage has usually fallen to less than 2, and after months of lactation may be less than $\mathrm{I}$. The content of protein is affected very little, if at all, by diet, as is shown by the agreement between the figures relating to peacetime United States (Bell, r928) and wartime Britain (Kon \& Mawson, I950). In the very first days the fall is more rapid where the output is greater. In the cow, the protein content of colostrum is reduced when milking is begun before calving, and a similar effect of antenatal 